\title{
SEDUM CLAUSENII (CRASSULACEAE), UNA NUEVA ESPECIE PARA LA FLORA DEL CENTRO DE MEXICO'
}

\author{
Emmanuel Perez-Calix \\ Instituto de Ecología, A.C. \\ Centro Regional del Bajío \\ Apartado postal 386 \\ 61600 Pátzcuaro, Michoacán
}

\begin{abstract}
RESUMEN
A partir de plantas colectadas en la región noreste del estado de Guanajuato y la centro-sur del de San Luis Potosí se describe y propone como especie nueva para la ciencia a Sedum clausenii. El nuevo taxon recuerda parcialmente a Sedum greggii Hemsl. y a Sedum grandipetalum Fröd., distinguiéndose de ellos en que las hojas de las ramas fértiles de $S$. clausenii son espatuladas a obovado-espatuladas, mientras que las otras especies presentan hojas elípticas a lanceoladas $u$ oblanceoladas.
\end{abstract}

\section{ABSTRACT}

Sedum clausenii is proposed and described as a new species, based on collections from northeastern Guanajuato and adjacent south-central San Luis Potosí, México. The new species most closely resembles Sedum greggii Hemsl. and Sedum grandipetalum Fröd., but differs from both in the leaves of the floriferous branches, which vary from spatulate to obovate-spatulate. Leaves of the other two species are elliptic to lanceolate or oblanceolate.

Durante la revisión de los especímenes del género Sedum (Crassulaceae), colectados en el área del Bajío y regiones adyacentes, se encontró una planta originaria de la porción noreste del estado de Guanajuato, de localidades ubicadas en los municipios de San Luis de la Paz, Victoria y Xichú; así como del municipio de Ríoverde, en el estado de San Luis Potosí. Al intentar identificarla, se observó que presenta características que no corresponden con las especies descritas anteriormente, por lo que se propone como nueva para la ciencia.

Sedum clausenii Pérez-Calix sp. nov. Fig. 1.

Planta herbacea chamaephyta papillosa, usque ad $15 \mathrm{~cm}$ longa, procumbens vel pendula; rami steriles breves, foliis dense imbricatis suborbicularibus vel late ovatis, 2-3.5 mm

1 Trabajo realizado con apoyo económico del Instituto de Ecología, A.C. (cuenta 902-03), del Consejo Nacional de Ciencia y Tecnología y de la Comisión Nacional para el Conocimiento y Uso de la Biodiversidad. 


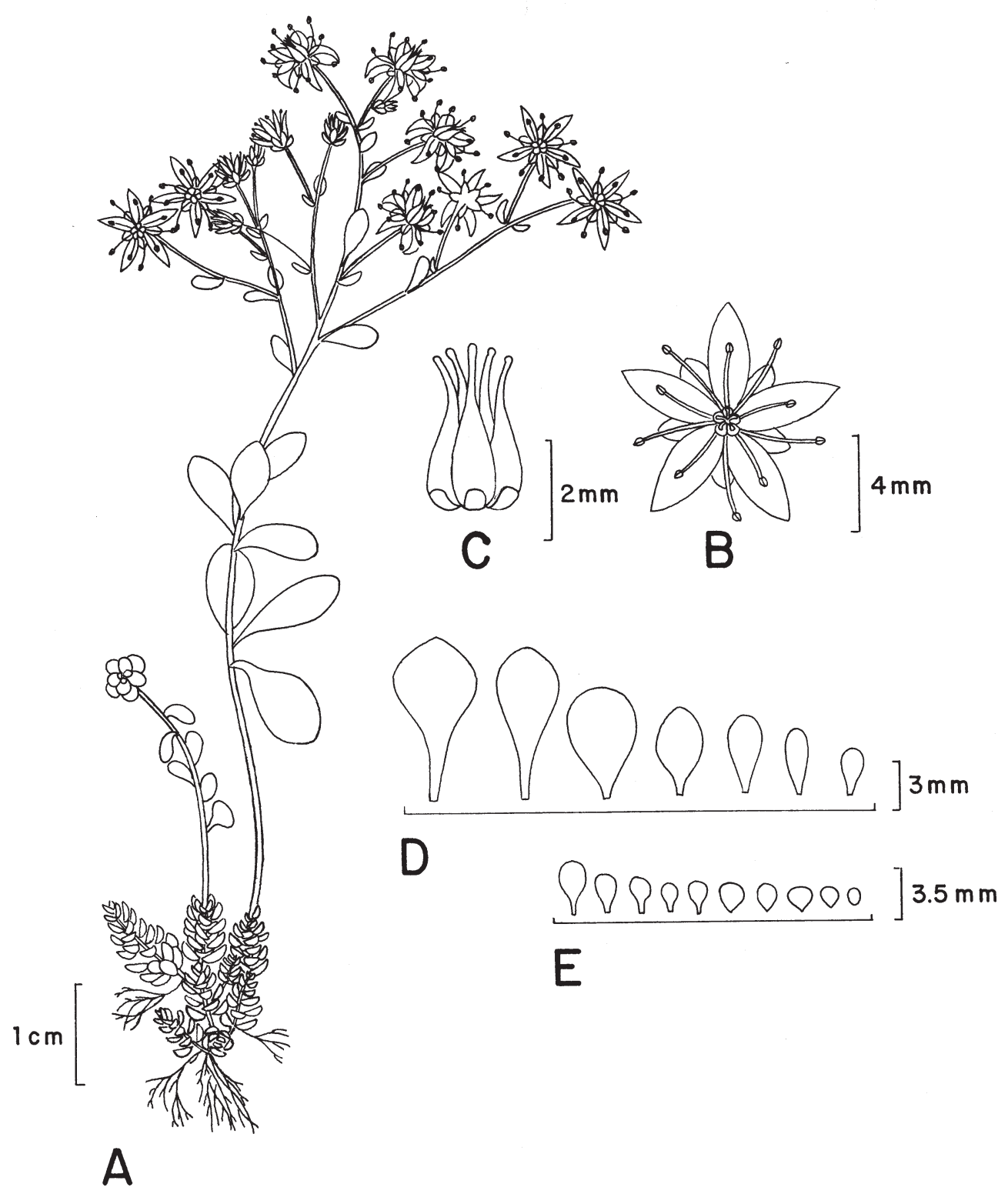

Fig. 1. Sedum clausenii Pérez-Calix. A. Aspecto general de la planta; B. Flor; C. Carpelos y nectarios; D. Variación de las hojas del tallo floral; E. Variación de las hojas de las ramas estériles. Dibujo realizado por Rogelio Cárdenas (con base en E. Pérez y S. Zamudio 3597 (IEB)). 
longis, 2-3 mm latis, (in foliis supernis) ad basim in segmentum petioliformem decrescentibus; rami floriferi elongati, foliis alternis, spathulatis, 6.5-16.5 mm longis, 4-8.5 mm latis, apice rotundatis et brevissime mucronatis; inflorescentia cymosa terminalis, pedicellis ca. $6 \mathrm{~mm}$ longis et $0.5 \mathrm{~mm}$ latis; flores pentameri; calyx ca. $0.5 \mathrm{~mm}$ diametro, sepalis oblanceolatis, 2-2.5 mm longis, 0.5-1.5 mm latis; corolla intense lutea, petalis ellipticis, $4 \mathrm{~mm}$ longis, $1.5-2 \mathrm{~mm}$ latis; nectaria subquadrata, ca. $0.4 \mathrm{~mm}$ longa; carpella ca. $2.5 \mathrm{~mm}$ alta, stylibus ca. $1 \mathrm{~mm}$ longis; folliculi erecti, seminibus plurimis.

Planta herbácea, perenne, caméfita, suculenta, glabra, papilosa, de hasta $15 \mathrm{~cm}$ de largo, procumbente o péndula; tallos glabros; ramas estériles muy cortas, dispuestas en la base de las ramas floríferas, con las hojas alternas, arrosetadas, muy densamente imbricadas, espatuladas, suborbiculares a ampliamente ovadas, de 2 a $3.5 \mathrm{~mm}$ de largo por 2 a $3 \mathrm{~mm}$ de ancho en la parte más amplia, ápice redondeado, en las hojas de la parte superior de la rama la base se angosta en un segmento pecioliforme, ligeramente espolonadas; ramas floríferas alargadas, la base con hojas (similares en forma y tamaño a las de las ramas estériles) densamente imbricadas, en la parte superior los entrenudos son más espaciados y las hojas son alternas, espatuladas a obovado-espatuladas con el ápice redondeado, ocasionalmente mucronulado, margen entero, suculentas; inflorescencias en forma de cimas terminales; pedicelos de cerca de $6 \mathrm{~mm}$ de largo y alrededor de $0.5 \mathrm{~mm}$ de grueso; flores pentámeras; cáliz de 5 sépalos oblanceolados, ligeramente desiguales en dimensiones, de 2 a $2.5 \mathrm{~mm}$ de largo por 0.5 a $1.5 \mathrm{~mm}$ de ancho, de color verde pálido; corola de cerca de $8 \mathrm{~mm}$ de diámetro, de color amarillo intenso, pétalos 5, libres, elípticos, de $4 \mathrm{~mm}$ de largo por 1.5 a $2 \mathrm{~mm}$ de ancho; nectarios subcuadrados, pequeños, de cerca de $0.4 \mathrm{~mm}$ de largo; carpelos erectos, fusionados cerca de la base, suberectos, estilos de $\pm 1 \mathrm{~mm}$ de largo; folículos erectos, con numerosas semillas; éstas de cerca de $0.3 \mathrm{~mm}$ de largo, de color café.

TIPO: México, Guanajuato, $3.5 \mathrm{~km}$ al norte de Joya Fría, camino a Puerto de Palmas, municipio de Victoria. Alt. $2300 \mathrm{~m}$. Bosque de encino-pino. E. Pérez y E. Carranza 3615 (Holotipo IEB; isotipos por distribuirse a CHAPA, ENCB y MEXU).

Material adicional examinado: Guanajuato: $\pm 12 \mathrm{~km}$ al NW de Mesas de Jesús, camino a San Antón, municipio de San Luis de la Paz, E. Pérez y E. Carranza 3607 (IEB); \pm 8 a $10 \mathrm{~km}$ al NW de Mesas de Jesús, municipio de San Luis de La Paz, E. Carranza 3949 (IEB); $\pm 3 \mathrm{~km}$ al $\mathrm{N}$ de Joya Fría, municipio de Victoria, E. Pérez y S. Zamudio 3597 (IEB); El Salto, municipio de Xichú, E. Ventura y E. López 9181 (IEB); Puerto del Ocotero, $\pm 1.5 \mathrm{~km}$ de San Agustín por el camino a Xichú, municipio de Xichú, E. Pérez y E. Carranza 3615 (IEB); Rincón Las Calabazas, $10 \mathrm{~km}$ al sur de Xichú, municipio de Xichú, E. Ventura y E. López 6558 (IEB).

San Luis Potosí: cerro El Agujón, cerca de El Zapote, aproximadamente $30 \mathrm{~km}$ al SSW de Ríoverde, municipio de Ríoverde, J. Rzedowski 25651 (ENCB).

Distribución: El nuevo taxon se conoce de la porción noreste del estado de Guanajuato y del sur de San Luis Potosí. Considerando las diferentes localidades en que se ha colectado, es muy probable que sea un endemismo de los bosques de pino-encino 
de la región, que incluye parte de los estados de San Luis Potosí, Guanajuato y Querétaro. Altitudinalmente se registra de 1700 a $2300 \mathrm{~m}$. Crece sobre rocas ígneas, de preferencia en paredes completamente verticales, en sitios cercanos a escurrimentos de agua. En algunas de las localidades citadas la nueva especie es simpátrica con Sedum greggii y con Sedum moranense H.B.K.

Fenología: Sedum clausenii es una planta caméfita, por lo que durante la etapa estéril de la especie los individuos se observan con las ramitas cortas, mientras que en su periodo de floración (finales de febrero a principios de mayo) se les encuentra con las ramas largas desarrolladas.

Etimología: El nombre de la nueva especie se dedica como homenaje al Profr. Robert T. Clausen (26.XII.1911 - 31.XII.1981) quien, durante gran parte de su vida, estudió el género Sedum. Entre sus obras destacan: Sedum of the Trans-Mexican Volcanic Belt: an exposition of taxonomic methods (1959), Sedum of North America North of Mexican Plateau (1975) y, Sedum (Crassulaceae) of the Mexican Cordilleran Plateau (1984).

Cuadro 1. Comparación de las hojas de las ramas floríferas de Sedum clausenii, Sedum greggii y Sedum grandipetalum.

\begin{tabular}{|l|cc|c|}
\hline Especie & $\begin{array}{c}\text { largo } \\
(\mathrm{mm})\end{array}$ & $\begin{array}{c}\text { ancho } \\
(\mathrm{mm})\end{array}$ & \\
\hline Sedum clausenii & $6.5-16.5$ & $4-8.5$ &
\end{tabular}


Por su apariencia general Sedum clausenii se puede ubicar en el grupo que Fröderström (1935) denominara como Alamosanum. Al parecer, las especies con las que muestra mayor afinidad son S. greggii Hemsl. y $S$. grandipetalum Fröd., ya que las tres son muy similares en su hábito, son herbáceas perennes, presentan ramas florales postradas o colgantes, son caméfitas, durante una época del año se les encuentra como plantitas con las ramas estériles muy cortas, con las hojas densamente imbricadas. Además, presentan flores con pétalos de color amarillo intenso y los nectarios son menores de $1 \mathrm{~mm}$ de largo. La principal diferencia la dan las hojas de las ramas floríferas, las que en Sedum clausenii son espatuladas a obovado-espatuladas en contraposición a las elípticas a lanceoladas u oblanceoladas de $S$. greggii y de $S$. grandipetalum. En el Cuadro 1 se comparan las hojas de las ramas floríferas de las tres especies.

\section{AGRADECIMIENTOS}

Se agradece al Dr. Jerzy Rzedowski R. la lectura crítica del manuscrito, además la traducción de la diagnosis al latín; al Biól. Eleazar Carranza González su amable compañía durante el trabajo de campo y al Biól. Sergio Zamudio Ruiz las sugerencias durante la preparación de esta contribución. El dibujo es obra del Sr. Rogelio Cárdenas.

\section{LITERATURA CITADA}

Fröderström, H. 1935. The genus Sedum L. A systematic essay. Part IV. Act. Hort. Goth. 10: 1-262. 